\title{
Anatomical approach of team formation in the study of the collective
}

\author{
Alexander Melentyev ${ }^{1 *}$, Evgeny Isakov $^{2}$, Nikolay Storchevoy ${ }^{1}$, and Dmitry Tokarev ${ }^{1}$ \\ ${ }^{1}$ Russian State Agrarian University-MSHA, 127550, Moscow, Timiryazevskaya street, 49 \\ ${ }^{2}$ Moscow State Technical University of Civil Aviation 125993, Moscow, Kronshtadtsky \\ Boulevard, 20
}

\begin{abstract}
Recently, in the practice and theory of management of general education systems, much attention has been paid to the formation and work with "teams" within a team of teachers. In the teaching environment, the concept of "team" is understood positively and is used very often, but not always in its direct meaning. By the thesis "teaching team" we mean a group of teachers who are prepared to achieve a common goal for the sake of joint activities and are responsible for the results obtained. Defining a group of teachers as a team does not mean creating it in reality, and the desire of management to force teachers to act as a team is not enough.
\end{abstract}

\section{Introduction}

Modernization of higher education as the main direction of investment in the development of human potential is a priority task.

Whose socio-economic development of the Russian Federation. The reform of the higher education system puts higher education institutions, respectively, and their teaching staff in rather difficult working conditions, especially in connection with the stricter requirements for accreditation. After receiving the certificate of accreditation for the next period, the university begins to prepare for a new accreditation. At the same time, " the quality of student training has not become the main object of state accreditation procedures for universities, which hinders the introduction of innovations in the educational process.

The tasks facing modern domestic universities are presented in their complex so important, complex and at the same time urgent that their solution requires maximum effort, a high degree of initiative and activity of each employee of the university. They have to be solved in the context of increasing requirements for publication activity and increasing the academic load of the teaching staff.

The main tasks of the university department are to meet the needs of students, postgraduates, and students of additional education courses in training or advanced training using innovative educational technologies, high-quality and modern scientific and methodological support for the educational process, and the expansion of fundamental and applied scientific research. In these conditions, the collective or group (team) work of the head of the department, teachers, graduate students and even students in the management processes

\footnotetext{
* Corresponding author: anmagesa@,mail.ru
} 
of the department is very important. Unfortunately, in this formulation of the question, university management is practically not studied.

The potential of a university can be defined as the ability of a complex of human and material resources of an educational institution of professional education to ensure the implementation of scientific and educational tasks that are important for society. The basis of the capabilities of each university is its personnel potential, which shows the characteristics of the quality of general education and scientific functions of the professional and pedagogical staff of the university. Human potential training vocational education not only shows the willingness of the teachers to perform their functions in the present, but also the totality of all of their abilities in the long run - given the age of the faculty, scientific and pedagogical qualifications, practical experience, business activities, quality activities (including "performance"), professional mobility and innovation, the level of professional motivation. It is the level of human resources that determines the quality of the university's academic work, and it is the university that is the object of management.

The process of developing scientific and pedagogical personnel potential is based on moral and mental potential. Therefore, its development is the main task in the process of developing the university's human resources potential. Since individual intelligence and morality are formed in the process of activity and communication, it becomes obvious that it is advisable to create special team teams focused on solving organizational, scientific, research, educational and educational goals of an educational institution.

Due to the specifics of the university's activities, which consist in the synthesis of scientific research and pedagogical activities, the" pedagogical team " within the scope of the study is understood by the author as a scientific and practical research group of teachers, which is organized according to the level of intellectual development, research and pedagogical experience, needs, motives and goals of professional activity.

When forming teams, the term "team building" is used, which is important for creating a methodology. Team building is understood by the author as an intra-collective process, which is aimed at harmonizing the relations of team members on the basis of common value and semantic goals.

Team building has the following objectives: to create a moral mood and good mood in the team; to develop professional skills for successful intellectual interaction of team members in various conditions; to increase the level of personal responsibility for results; to move from a state of competition to cooperation; to improve the level of trust, care and mutual assistance between team members; to switch individual value and semantic orientations of participants from themselves to the team.

\section{The difference between the departments of physical culture and other departments in the University}

The difference between the Departments of Physical Culture and other departments in the University lies in the discipline "Physical Culture and Sport", which is multi-faceted and has many features.

The first feature is that the discipline is aimed at improving the physical body of a person, its harmonious development, and aspects of improving physical fitness.

The second distinctive feature is the unique contingent of the faculty teaching the discipline "physical culture and sports" at the University. The basis of the teaching staff of the Department of Physical Culture is made up of specialists, in the past athletes who have achieved certain results in their fields, which are reflected in the titles and categories. To achieve heights in sports, a person must have moral and strong-willed qualities, psychological and physical training, organizational skills and skills. After completing their sports career, 
specialists transfer their knowledge, skills and experience to their professional activities at the university, if they decide to work in the field of education.

The third distinctive feature is the practical and applied significance of the discipline "physical culture and sports", in which the expression "theory without practice is dead, practice without theory is blind" acquires the most relevant meaning. The greater the gap between practice and theory, the more mistakes occur in teaching the discipline. The teaching of the discipline "physical culture" mainly involves practitioners who rely on the experience of their sports activities, armed with methodological and scientific developments in the field of healthsaving technologies. A sports theorist who accidentally falls into the environment of the Department of Physical Culture, breaks out of the general concept of the practical work of the department, sometimes violating the established relations and the work of the team with his actions. For such an individual, there are two ways-self-education, and acceptance of the conditions of work in the team, or confrontation, leading to his removal from the cathedral community.

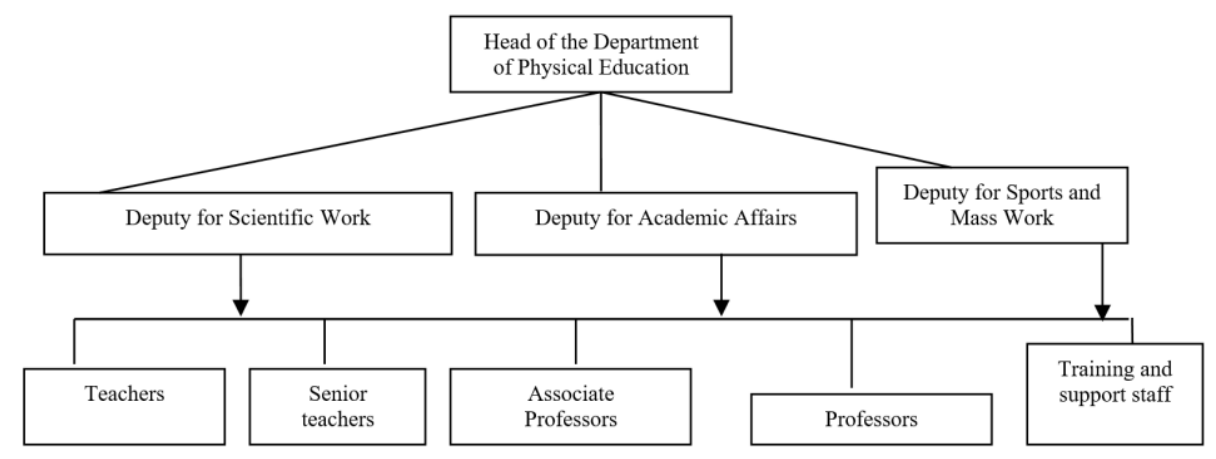

Fig. 1. Formal organizational structure of the Department of Physical Education.

Effective implementation of educational technologies for training specialists and the organization of scientific work in the departments is possible only if the appropriate organizational, personnel and material conditions are created, which, in turn, requires large resources. For optimal use of these resources, the activities of the department should be carried out on the basis of a flexible organizational and functional management structure.

The management structure of the graduating department includes five functional blocks: the department's development strategy and external relations, academic work, scientific work, social work, material and technical support of the department's activities. Human resources and social work management means that the head of the department, like any manager, must manage the staff of his department. Material and technical support of the department's activities is the creation of conditions for the implementation of the functions of teachers and employees of the department, the interested participation of personnel in the management and life of the department's staff. The main blocks of the management structure are supervised by the deputy head of the department, in particular, by the deputies for academic and scientific work. The entire staff of the department participates in the development and continuous improvement of such a structure: teachers, postgraduates and even active students. This improves the quality of the management structure, improves its psychological perception, and increases the reliability of the implementation of decisions made at the department. The conceptual tasks of management include the development of the concept of activity of the department, the creation of a system of both collective and individual motivation and are solved by the highest level of management of the department - the head. In the solution of 
strategic tasks of the Department, characterized by long-term consequences, take part except the head, his deputies and leading teachers - "team" head of the Department.

\section{Approaches to the formation of teams.}

The structure of any university department can be divided into formal and informal. The formal organizational and functional structure of any university department is described in the orders and instructions of the Ministry of Education.

The informal structure is the subject of research and at the moment there is no single approach to the description of this phenomenon. But it is this informal structure that can make a formal team of teachers at the Department of Physical Education a teaching team.

The main approaches to team formation are based either on the results of transactional analysis developed by Eric Bern, or on the typology of team members ' personalities according to the Myers-Briggs model, or on the role models of Meredith Belbin, or on the models of sociotypes on which A. Augustinaviciute's socionics is based.

The creation of teaching teams is a relatively new scientific problem, which is psychological, complex and pedagogical in nature and needs a theoretical justification, taking into account the principles and laws of the functioning of the organization .

Study. The need to find solutions to these problems has identified the tasks of research activities. In terms of theory, these tasks lie in the field of pedagogy, sociology, psychology and physical culture to justify the formation of a team of teachers at the university. In terms of practice-the definition of conditions that contribute to the formation of a teaching team.

The object of the study is the teaching staff as a system of highly professional relations.

The subject of the research is the psychological and pedagogical support of the pedagogical process of creating a team of teachers in the conditions of a university.

The aim of the study was to find theoretical ways to substantiate the content of types, means and methods of general pedagogical and psychological support for the creation of a teaching team in a higher school environment.

The hypothesis of the study was the assumption that if a team of teachers of an educational organization performs joint work on the implementation of a pedagogical project related to the unity of motives, goals, tasks and values of teaching work, then the creation of a team in this team becomes possible using an approach that differs from the four approaches already known to us, namely, using the anatomical method of creating a team. The anatomical approach is based on the organizational method of team formation.

\section{Methods of study}

To fulfill the set goals and evaluate the given assumptions, a set of complementary theoretical and empirical approaches was taken, which are aimed at the subject of the study: 1) theoretical evaluation of scientific literature sources on pedagogical and educational psychology, philosophy, managerial and social psychology, pedagogy; conceptual analysis of completed dissertation research works on a similar topic; 2) methods of organization; 3) methods of collecting experimental materials; 4) methods of processing the results of experimental research activities (determination of the percentage coefficient and average statistical indicators, as well as the significance of empirical indicators using the Fisher F-test and the Gossett T-test of William Seeley (Student).

Experimental base of the research was teachers of departments of physical education REU im. G. V. Plekhanov, as well as Russian state agrarian University - Moscow agricultural Academy named after im. K. A. Timiryazev.

\section{Stages of studying:}


On the theoretical I-search phase (2013). it produced a study on the situation of educational reality, a certain experience of teaching groups in terms of awareness of their teachers ' teams, departments of physical culture. This made it possible to determine the means of general pedagogical and general psychological support for the education of teams of teachers at the university. The analysis of the literature on pedagogy and General psychology, as well as a number of research materials, allowed to argue early position of the study: determination of the problems of the object, subject, goals, disclosure of the thesis "the team of teaching staff," the argumentation of the General psychological characteristics of a team of teaching staff to determine the basis of the methodology, the development of a hypothesis and sampling methods.

Phase II of the study (2013-2014) in the course of testing and experimental work was carried out the analysis of the peculiarities of psychology, the number of lectivo higher educational institutions, the characteristics of reflection by the teachers of its membership in teaching teams, their organizations, which helped to clarify and test hypotheses research activities. The plan of psychological and pedagogical equipment of processes of creation of teams of teachers is developed and introduced. It included a method of argumentation of the content, conditions of implementation in the aspect of correction and improvement of general psychological phenomena that are inherent in team teams that are united by a common goal of joint work.

At the third evaluation and diagnostic stage (2014-2015), the results of empirical research activities were grouped and analyzed, and the results of the previous stages were compared. The role of the training of creating a team of teachers in the aspect of improving the indicators of unity and cooperation of its participants is determined.

\section{The results of the study}

As a result of the research, four methods of team organization were studied, and the prerequisites for the creation of a fifth method of team formation, which is based on the anatomical approach, were revealed. In this case, this approach is based on the construction of a model of the teaching team, in which each of its participants must correspond to some organ of the human body. This analogy is based on the assumption that the oldest, well - functioning team known to man is his body.

The anatomical approach of team formation allows you to get significant advantages in relation to other approaches to solving this problem. These benefits include:

- a block diagram of a team;

- a clear understanding of the informal functional responsibilities of each of her team;

- matching the formal and informal roles of team members;

- determining the upper and lower limits of the number of team members;

- the ability to operate with a large number of team members by dividing them into several teams and creating points of interaction between them;

- getting a real opportunity to form a team under the leader;

In the anatomical approach, the formation of a team is possible only in one form of management - when the leader manages.

In the process of team building, people come together for joint activities on completely different principles than in the classical models of the administrative school of management. A favorable socio-psychological climate, creative atmosphere and team spirit, mutual understanding, trust, mutual support and consensus can be achieved under some conditions, the main of which is the identification of all members of the team of personal and group goals and a sense of mutual responsibility for the actions of each team member.

Within each functional block of tasks there are key elements that ensure the quality and effectiveness of the department's work on this block of problems. Each element is assigned to a 
teacher or graduate student of the department, who is able to show responsibility, initiative, organizational skills and personal skills. For each element of the department's management structure, target tasks, operational and long-term measures, and a control system are developed.

The effectiveness of the organizational and functional management structure of the department

largely depends on the reasonable division of rights and responsibilities across levels of governance. This affects the efficiency of decisions, coordination of actions, and the efficiency of using the cathedral's resources.

\section{References}

1. J. Pollack, P. Matous, Journal of International Project Management, 37, 473-484 (2019)

2. M.L. Shuffler, D. DiazGranados, E. Salas, Current Directions in Psychological Science, 20(6), 365-372 (2011)

3. M.L. Shuffler, D. DiazGranados, E. Salas, Current Directions in Psychological Science, 20(6), 365-372 (2011)

4. A.A. Babina, Theory and Practice of Physical Culture, 3, 6 (2017)

5. A.V. Smyshlyaev, L.G. Smyshlyaeva, K.A. Smyshlyaev, A.V. Belousov, Theory and Practice of Physical Culture, 3, 5 (2017)

6. E.A. Petrova, M.A. Kovaleva, D.V. Semenov, V.A, Morozov, Theory and Practice of Physical Culture, 4, 1 (2017)

7. V.V. Fedorov, L.V. Blinov, Theory and Practice of Physical Culture, 7, 5 (2017)

8. L.B. Andryushchenko, G.B. Kondrakov, A.G. Rostevanov, E.Y. Vnukova, A. Burov, Theory and Practice of Physical Culture, 9, 1 (2017)

9. N.S. Panchuk, Sh.Z. Khubbiev. V.E. Smirnov, et al., Theory and Practice of Physical Culture, 10, 3 (2017)

10. S.N. Gorshenina, N.A. Marinkina, A.R. Mamayev, Theory and Practice of Physical Culture, 11, 4 (2017)

11. S.B. Seryakova, G.V. Nikitovskaya, Theory and Practice of Physical Culture, 3, 10 (2018)

12. A.I. Fedorov, R.V. Khomenko, E.V. Antropova, I.V. Safina, Theory and Practice of Physical Culture, 5, 4 (2018)

13. V.E. Zhabakov, T.V. Zhabakova,Theory and Practice of Physical Culture, 6, 6 (2018)

14. L. Kardeliene, A. Sharkauskiene, Theory and Practice of Physical Culture, 8, 33 (2018)

15. A.V. Karavan, R.M. Kadyrov, Theory and Practice of Physical Culture, 9, 9 (2018)

16. R.K. Serezhnikova, N.Y. Shtreker, I.P. Krasnoshchechenko, V.I. Kolesov, Theory and Practice of Physical Culture, 10, 32 (2018)

17. A.A. Peredelsky, A.A. Shlyakhtov, O.Z. Ipatieva, Theory and Practice of Physical Culture, 9, 1 (2019) 